\title{
Obituary
}

\section{J. Goslings, Professor of Rheumatology, University of Leiden}

Hans Goslings, who died in October, will be deeply mourned, not only by his devoted family and his wide circle of friends and colleagues in Holland, but by those (particularly in England) who knew him throughout the world. Here in England he had a very special place in our hearts and will always be remembered by those of us who had the privilege of knowing him as a friend or teacher. Modest as he was, he towered as a giant-gigantic energy, gigantic enthusiasm, and perhaps above all gigantic good humour and joie de vivre. Any gathering that included Hans and his wife Cor was a success.

By history he will be remembered not only for his role in the East Indies and his work in the rebuilding of university medicine after the war, but for his continuing participation with Professor Querido in guiding the ancient and celebrated University of Leiden into the modern period and above all for the successful establishment of the first Rheumatism Research Unit on the European continent. There had been many distinguished clinical rheumatologists in Europe, including such founding fathers as Van Breemen in Holland, Forestier in France, and Schoen in Germany, to go back only as far as the years before the 2nd World War, but his was the first and for a time the only Unit with immunological, microbiological, pathological, biochemical, and clinical experts working together and in collaboration with other academic departments in the University. This Unit made significant contributions to the field over many years and Hans Goslings held it together with his inspiration and enthusiasm. He presided over several very high-spirited and intense joint meetings of the Heberden and Dutch Rheumatism Societies, and was invited to give the Heberden Round in 1958, taking as his subject 'Pericarditis in the Rheumatic Diseases'. Many people will also remember the very successful International Congress of Rheumatology at the Hague, a most happy occasion, the organization of which owed a great deal to him and his colleagues and friends throughout Holland. The heartfelt tributes of his colleagues, pupils, and friends are to be found in an excellent Festschrift, published in the Nederlandsch Tijdschrift voor Geneeskunde (unfortunately for us, mostly in Dutch). We send our deepest sympathy to his wife, Cor, who partnered him so ably and graciously in his open-hearted hospitalities, and to his children, in their varied professions.

E. G. L. BYWATERS 